\title{
Incidence of Febrile Urinary Tract Infections in Children after Successful Endoscopic Treatment of Vesicoureteral Reflux: A Long-Term Follow-Up
}

\author{
Manuela Hunziker, MD, Nochiparambil Mohanan, FRCSI, Federica D’Asta, MD, and Prem Puri, FRCS, FAAP (Hon)
}

Objective To evaluate the incidence of febrile urinary tract infection (UTI) after successful endoscopic correction of intermediate and high-grade vesicoureteral reflux (VUR).

Study design Medical records of 1271 consecutive children (male, 411; female, 903) who underwent successful endoscopic correction of VUR were reviewed. Factors potentially influencing postoperative UTIs, such as history of presentation, age, sex, grade of VUR, renal scarring, and agent used for the endoscopic injection, were analyzed. Results Febrile UTI developed in 73 children (5.7\%) after successful endoscopic correction of VUR. Thirty-nine children had a single episode of UTI, and 34 children had two or more episodes at 1 month to 5.9 years (median, 1 year) after correction of VUR. With multivariate analysis, female sex $(P<.001)$, history of preoperative bladder/ bowel dysfunction (BBD; $P=.005)$, and BBD after endoscopic correction $(P=.001)$ were revealed to be the most important independent risk factors for a febrile UTI after successful correction of VUR.

Conclusions The incidence of febrile UTIs after successful correction of intermediate and high grade VUR is low. Female sex and BBD were the most important risk factors in the development of febrile UTI. Our data supports the importance of assessing bladder and bowel habits in older children with febrile UTIs after endoscopic correction of VUR. (J Pediatr 2012; $\mathbf{\square}: \mathbf{\square}-\mathbf{\square})$.

esicoureteral reflux (VUR) is the most common urinary tract abnormality in pediatrics, occurring in $1 \%$ to $2 \%$ of children, including $30 \%$ to $40 \%$ of children with urinary tract infection (UTI) ${ }^{1,2}$ The association of VUR, febrile UTI, and renal parenchymal damage is well recognized. Reflux nephropathy is a cause of childhood hypertension and chronic renal failure. ${ }^{3}$ Marra et al reviewed data on children with chronic renal failure who had high-grade VUR in the Italkid project, a database of Italian children with chronic renal failure, and found that those with VUR accounted for $26 \%$ of all children with chronic renal failure. The various treatment options currently available for VUR are: (1) long term antibiotic prophylaxis; (2) open surgical treatment; (3) minimally invasive endoscopic treatment; and (4) observation or intermittent therapy with management of bladder/bowel dysfunction (BBD) and treatment of UTI as they occur.

Since United States Food and Drug administration approval in 2001 of dextranomer hyaluronic acid (Dx/HA) as a tissue augmenting substance for subureteral injection, endoscopic treatment has become a widely accepted minimally invasive alternative in the management of VUR.

The main goals of treatment of children with VUR are to prevent renal parenchymal damage and morbidity associated with recurrent febrile UTIs. Relatively few studies have examined the incidence of febrile UTIs after successful resolution of VUR with endoscopic injection. The duration of follow-up in most series has been short, with conflicting rates of incidence of UTI. Febrile UTIs after successful resolution of VUR have been reported at rates as low as $2.2 \%$ to as high as $27 \%$ of patients. ${ }^{4-9}$ The aim of this study was to determine the incidence of febrile UTIs in a large cohort of patients with intermediate and high-grade VUR treated endoscopically.

\section{Methods}

We retrospectively reviewed the records of 1314 consecutive children with primary grade III to V VUR, who underwent successful endoscopic correction of VUR between 1998 and 2007. Patients with VUR caused by neuropathic bladder, posterior urethral valves, and ureteroceles were excluded from the study. Forty-three children (3.3\%) were lost to follow-up after successful endoscopic correction. The remaining 1271 children comprised our study group and were included for analysis. Children with grade II VUR were given endoscopic treatment only when grade II refluxing ureters were associated with high-grade VUR on

$\begin{array}{ll}\text { BBD } & \text { Bladder/bowel dysfunction } \\ \text { DMSA } & \text { Dimercapto-succini acid } \\ \text { Dx/HA } & \text { Dextranomer hyaluronic acid } \\ \text { UTI } & \text { Urinary tract infection } \\ \text { VCUG } & \text { Voiding cysturethrography } \\ \text { VUR } & \text { Vesicoureteral reflux }\end{array}$

BBD Bladder/bowel dysfunction

Dx/HA Dextranomer hyaluronic acid

UTI Urinary tract infection

VUR Vesicoureteral reflux
From the National Children's Research Centre, Our Lady's Children's Hospital, and National Children's Hospital, Dublin, Ireland

The authors declare no conflicts of interest.

0022-3476/\$ - see front matter. Copyright ๑ 2012 Mosby Inc. All rights reserved. 10.1016/j.jpeds.2011.12.033 
the contralateral side. VUR was diagnosed in all children with voiding cysturethrography (VCUG) and graded according to the International Classification Systems (International Reflux Study Committee). Endoscopic treatment was completed on an outpatient basis according to a previously described technique. ${ }^{10-12}$ The tissue augmenting substance used for endoscopic injection was Teflon (polytetrafluoroethylene, PTFE, Ethicon, Inc, Somerville, New Jersey) from 1998 to 2000. Since United States Food and Drug administration approval in 2001 of Dx/HA (Oceana Therapeutics, Inc, Edison, New Jersey), Dx/HA has been used. Antibiotic prophylaxis was continued after the endoscopic procedure, until voiding cystourethrography and renal ultrasound scanning were performed after 3 months. When voiding cystourethrogram showed resolution of reflux (grade 0-I), antibiotics were stopped. A febrile UTI was diagnosed when results of a urine culture showed a bacterial count $>10^{5}$ and grew a single organism accompanied by a temperature $\geq 38.5^{\circ} \mathrm{C}$. In addition to fever, 8 patients also had dysuria and frequency. In infants, the urine sample was collected with a urine bag. A midstream urine sample was obtained and examined in older children.

Factors potentially influencing postoperative UTIs, including preoperative history of presentation (such as UTI, prenatal hydronephrosis, sibling VUR, or BBD), sex, age, agent used for the endoscopic injection, grade of VUR, renal scarring on preoperative dimercapto-succini acid (DMSA) scans and postoperative BBD, were analyzed. In addition, the number of endoscopic treatments needed for resolution of VUR was noted. Patients in whom febrile UTIs developed after successful endoscopic correction of intermediate and high grade VUR were classified as group I. Children in whom febrile UTIs did not develop were classified as group II. In patients in group I, the incidence of recurrence or neocontralateral VUR was evaluated. Detailed information was obtained in patients with BBD. We considered children to have $\mathrm{BBD}$ when their chart review revealed urgency, frequency and/or daytime incontinence, infrequent voiding, and constipation. BBD was treated with regular voiding, timed voiding, complete bladder emptying, increased fluid intake during daytime, and reduced fluid intake in the evening. We also addressed bowel habits, such as the importance of regular bowel movements, increased fiber intake, and laxatives when indicated before endoscopic injection.

Renal scarring was evaluated with DMSA scintigraphy and classified in 3 groups: mild (focal defects in uptake between $40 \%$ and $45 \%$ ), moderate (uptake of renal radionuclide between $20 \%$ and $40 \%$ ), and severe (shrunken kidney with relative uptake $<20 \%$ ). DMSA scans were performed at least 4 to 6 months after an initial UTI.

As part of our standard policy, patients were observed 3 months after the endoscopic treatment with a routine VCUG and renal ultrasound scan. Renal and bladder ultrasound scanning were performed again at 1 year and then every 2 years thereafter for long-term follow-up, to monitor the appearance of the upper urinary tract and the site and size of the subureteral Dx/HA co-polymer implant.
Parents were instructed to report when their child developed a symptomatic UTI. They were asked to bring details of treatment and urine culture reports when the children were treated locally by general practitioners. A repeat VCUG after successful endoscopic treatment was performed when the children had two or more documented febrile UTIs or showed pelvicalyceal dilatation on renal ultrasound scanning after the first febrile UTI. We observed these children from 3.5 years to 13.5 years (mean follow-up period, 7.6 years).

The $\chi^{2}$ test and Mann Whitney $U$ test were used for statistical analysis of the data, and multiple logistic regression analysis was used to identify independent variables for the risk factors of febrile UTIs in children after successful endoscopic treatment of VUR, with a $P$ value $<.05$ considered to be statistically significant.

\section{Results}

Of the 1271 children, 863 were girls and 408 were boys, and the median age at the time of endoscopic injection was 1.6 years (range, 2 month-13.3 years). The reflux was unilateral in 637 patients and bilateral in 634 patients, comprising 1905 refluxing ureters. Grade of VUR at the time of endoscopic treatment was grade II in 76 refluxing units (4\%), grade III in 1047 refluxing units (55\%), grade IV in 737 refluxing units $(39 \%)$, and grade $\mathrm{V}$ in 45 refluxing units (2\%). All children with grade II VUR had high-grade reflux on the contralateral side. The indications for VCUG in the 1271 children were UTIs in 1135 (89.3\%), screening for sibling VUR in $80(6.3 \%)$, urinary incontinence without a history of UTI but with pelvicalyceal dilatation on ultrasound scanning in $51(4 \%)$, and prenatally diagnosed hydronephrosis in $5(0.4 \%)$. Children with BBD were 3.0 to 12.1 years old (median, 10.2 years) at the time of injection therapy. Polytetrafluoroethylene was used for endoscopic injection in 253 patients and Dx/HA in the remaining 1018 patients.

Febrile UTI developed in 73 children (5.7\%) after successful endoscopic correction of intermediate and high-grade primary VUR, and febrile UTIs did not develop in 1198 children $(94.3 \%)$. Details of the demographics of all patients are summarized for the infection group and infection-free group in Table I, which also gives information about descriptive statistics for factors that may predict post-treatment UTI. Twelve children (16.4\%) with febrile UTIs after resolution of VUR were hospitalized for intravenous antibiotic therapy, and 61 children $(83.6 \%)$ were treated with oral antibiotics. UTI developed in the first year in 40 children (55\%), in the second or third year in 24 children (33\%), and 3 years after resolution of VUR in 9 children (12\%). Thirty-four children had two or more episodes of UTIs, and 39 children had a single episode of UTI. Febrile UTIs developed 1 month to 5.9 years (mean, 1 year) after endoscopic correction of VUR. Escherichia coli were the most common organisms (90\%) isolated in urine cultures, followed by Proteus mirabilis (7\%) and Pseudomonas aeruginosa (3\%). 
Table I. Factors analyzed for assessing prediction of febrile UTI after successful correction of VUR

\begin{tabular}{|c|c|c|c|}
\hline & $\begin{array}{c}\text { Group } 1 \\
n=73 \\
\text { (febrile UTI) }\end{array}$ & $\begin{array}{c}\text { Group } 2 \\
n=1198 \\
\text { (no febrile UTI) }\end{array}$ & $\begin{array}{c}P \\
\text { value }\end{array}$ \\
\hline \multicolumn{4}{|l|}{ Sex } \\
\hline Female & $64(7.4 \%)$ & 799 (92.6\%) & $<.001$ \\
\hline Male & $9(2.2 \%)$ & 399 (97.8\%) & \\
\hline \multicolumn{4}{|l|}{ Presentation } \\
\hline UTI & $59(5.2 \%)$ & 1076 (94.8\%) & \\
\hline BBD & $11(21.6 \%)$ & 40 (78.4\%) & $<.001$ \\
\hline Prenatal diagnosis & $0(0 \%)$ & $5(100 \%)$ & \\
\hline Screening for sibling VUR & $3(3.8 \%)$ & 77 (96.2\%) & \\
\hline \multicolumn{4}{|l|}{ Age in years } \\
\hline Median (range) & $3.0(0.2-9.5)$ & $1.6(0.1-13.3)$ & .001 \\
\hline \multicolumn{4}{|c|}{ Agent for injection in $\mathrm{n}$ of patients } \\
\hline Teflon & $24(9.5 \%)$ & $229(90.5 \%)$ & .004 \\
\hline Deflux & $49(4.8 \%)$ & $969(95.2 \%)$ & \\
\hline \multicolumn{4}{|l|}{ VUR laterality } \\
\hline Unilateral & 33 & 604 & .387 \\
\hline Bilateral & 40 & 594 & \\
\hline \multicolumn{4}{|l|}{ Grade of VUR } \\
\hline$\|$ & 4 & 72 & \\
\hline III & 66 & 981 & .805 \\
\hline IV & 40 & 697 & \\
\hline V & 3 & 42 & \\
\hline \multicolumn{4}{|l|}{$\mathrm{n}$ of injections } \\
\hline 1 injection & $98(6.0 \%)$ & 1528 (94.0\%) & \\
\hline 2 injections & $13(5.3 \%)$ & $231(94.7 \%)$ & .479 \\
\hline 3 injections & $2(5.7 \%)$ & $33(94.3 \%)$ & \\
\hline \multicolumn{4}{|c|}{ BBD after endoscopic correction } \\
\hline Yes & $23(20.0 \%)$ & $92(80.0 \%)$ & $<.001$ \\
\hline No & $50(4.3 \%)$ & $1106(95.7 \%)$ & \\
\hline
\end{tabular}

All variables were compared with $\chi^{2}$ test, except for age, for which Mann-Whitney U test was used.

Female sex $(P<.001)$, older age of patients $(P=.001)$ and Teflon as a tissue augmenting substance $(P=.004)$ were shown to contribute to a higher likelihood of febrile UTI after successful endoscopic correction.

In the children in whom febrile UTI developed after endoscopic correction of VUR, the reflux at initial evaluation was unilateral in 33 and bilateral in 40 . The grade of VUR at diagnosis was grade II in 4 ureters, grade III in 66 ureters, grade IV in 40 ureters, and grade $V$ in 3 ureters. Only 43 of 113 ureters $(38 \%)$ had grade IV or V VUR. There was no significant difference in the grade of VUR between the children in whom UTI developed (group I) and the children without UTI (group II) after correction of VUR.

Of the 73 children who had UTI after correction of VUR, the reflux resolved in 98 refluxing units $(86.7 \%)$ after one endoscopic injection. The reflux resolved after two injections in 13 refluxing units $(11.5 \%)$ and after a third injection in two refluxing units $(1.8 \%)$. This is comparable with the outcome of endoscopic treatment in children in whom UTI did not develop after resolution of VUR.

All children in group I and 1057 of 1198 children in group II had a DMSA scan to evaluate the renal parenchymal damage. The incidence of renal scarring in group I with febrile UTI after correction of VUR was 37\%, compared with $25.6 \%$ in group II without UTIs $(P=.031)$. Renal scarring was also significantly higher in girls in group $I,(n=24$, $37.5 \%)$ compared with girls in group II $(\mathrm{n}=168,24 \%$;
Table II. Renal scarring in children with or without febrile UTI after endoscopic treatment of VUR

\begin{tabular}{lccc} 
Renal scarring & $\begin{array}{c}\text { Group I (febrile UTI) } \\
\mathbf{n = 7 3}\end{array}$ & $\begin{array}{c}\text { Group II (no febrile UTI) } \\
\mathbf{n = 1 0 5 7}\end{array}$ & P value \\
\hline Mild scarring & 14 & 134 & \\
Moderate scarring & 11 & 105 & \\
Severe scarring & 2 & 32 & \\
Total scarring & $27(37 \%)$ & $271(25.6 \%)$ & .031 \\
No scarring & $46(63 \%)$ & $786(74.4 \%)$ & \\
\hline
\end{tabular}

$P=.027)$. Table II shows mild, moderate, and severe scarring after endoscopic correction of VUR in group I and group II.

All children in group I who had episodes of febrile UTI underwent renal ultrasound scanning. At ultrasound scanning, there was no evidence of delayed vesicoureteral junction obstruction or significant changes in the size the injected mound. However, in 3 patients, dilatation of the pelvicalyceal system was shown after the first febrile UTI. We performed VCUG in all children who had two or more febrile UTIs after endoscopic treatment or had pelvicalyceal dilatation on ultrasound scanning after first febrile UTI. Thirtyfour children had two or more UTIs, and all these children underwent VCUG. Three children showed prominence of the pelvicalyceal system after first febrile UTI and also underwent VCUG. Four patients had recurrence of VUR, and another 3 patients had neocontralateral VUR on repeat VCUG. In patients who had recurrence of VUR, the grade was grade III in 3 ureters and grade IV in two ureters (unilateral -3 , bilateral -1). The grade of reflux in patients with neocontralateral VUR was II in one patients and III in two patients. The VUR was corrected after a single endoscopic injection in both recurrent and neocontralateral VUR. Six of the 9 boys in whom UTI developed after treatment were circumcised.

Occurrence of BBD before and after correction of VUR is shown in Table I. Eleven patients (15.1\%) in group I had known BBD, and 40 patients (3.3\%) in group II had BBD before endoscopic treatment of VUR. BBD after endoscopic correction was seen in 23 children (31.5\%) in group I, with 10 of these children also having BBD before endoscopic treatment. In group II, 92 children $(7.7 \%)$ had BBD after correction of VUR, with 17 of them also having BBD before correction of VUR. Overall, BBD was cured in only one patient in group I and 23 patients in group II after endoscopic correction of VUR. In 13 of the 23 patients in group I and 75 of the 92 patients in group II discovered to have BBD after correction of VUR, BBD were considered to be either newly diagnosed or misdiagnosed preoperatively as not having voiding dysfunction.

Twenty-three children (31.5\%), all girls, had a positive history of BBD after endoscopic correction of VUR diagnosed at a median age of 6.5 years (range, 4.2-10.2 years). The incidence of post-treatment voiding dysfunction was significantly higher in patients in whom febrile UTIs developed after endoscopic correction of VUR compared with patients without UTIs $(P<.001)$. 
In univariate analysis with logistic regression, a history of a UTI ( $P=.018$; OR, $2.1 ; 95 \%$ CI, 1.1-3.8) and BBD before endoscopic treatment $(P<.001$; OR, 5.1; 95\% CI, 2.5-10.5) were shown to be significant risk factors for post-treatment UTI.

Multivariate analysis revealed that female sex $(P<.001$, OR, 3.8), polytetrafluoroethylene injection $(P=.019$, OR, $1.9)$, a history of preoperative $\mathrm{BBD}(P=.005 ; \mathrm{OR}, 3.5)$, and BBD after endoscopic correction $(P=.001$; OR, 2.9) were the most important independent risk factors for a UTI after successful endoscopic treatment of VUR (Table III). Renal scarring and high-grade VUR were not significant factors.

\section{Discussion}

Endoscopic injection therapy has become a widely accepted treatment for VUR. Parental preference plays a major role in the selection of endoscopic treatment compared with longterm antibiotic treatment or open surgical treatment. The endoscopic treatment is safe and effective and performed as an outpatient procedure. However, ureteral re-implantation, either extravesical or intravesical, involves an incision on the lower abdomen and usually requires urethral catherization and hospitalization. The outcome of endoscopic treatment depends on the experience of the surgeon, and in experienced hands, it is comparable with that of open surgical treatment. ${ }^{10-12}$

Relatively few studies have examined the incidence of febrile UTIs after successful treatment of VUR, either with open ureteral reimplantation or endoscopic injection. In the final report of International Reflux Study in children, Jodal et al reported a 13\% (17 of 125) incidence of febrile UTIs after open surgical treatment in a 10 -year period. ${ }^{13}$ Elmore et al reported an incidence of febrile UTIs in $24 \%$ of children after reimplantation of ureters. ${ }^{6}$

In their meta-analysis study of reflux resolution and UTI after endoscopic treatment of VUR, Elder et al reported a $6 \%$ incidence of UTI and only $0.75 \%$ incidence of pyelonephritis. ${ }^{14}$ Similarly Lackgren et al reported after a mean follow-up of 5 years (range, 2-7.5 years) an 8\% (19 of 228) incidence of UTI and a 3.5\% (8 of 228) incidence of pyelonephritis after successful endoscopic treatment (Table IV). ${ }^{7}$ Chi et al noted $24 \%$ incidence of symptomatic UTI, onehalf of these were febrile (12\%) after reflux resolution with Dx/HA injection in a median follow-up of 2.6 years. ${ }^{8}$ In their study of 40 children who had successful endoscopic

Table III. Multivariate analysis of risk factors predicting febrile UTI after endoscopic injection

\begin{tabular}{lcc}
\hline & $\boldsymbol{P}$ value & OR (95\% CI) \\
\hline Female sex & $<.001$ & $3.8(1.8-7.9)$ \\
Polytetrafluoroethylene injection & .019 & $1.9(1.1-3.3)$ \\
Grade IV, V VUR & .931 & $1.0(0.6-1.7)$ \\
Preoperative BBD & .005 & $3.5(1.4-8.3)$ \\
Renal scarring on preoperative DMSA scan & .085 & $1.6(0.9-2.7)$ \\
BBD after endoscopic treatment & .001 & $2.9(1.5-5.5)$ \\
\hline
\end{tabular}

Dx/HA injection, Elmore et al reported an incidence of 5\% febrile UTIs after correction of VUR with endoscopic treatment. ${ }^{6}$ Sedberry-Ross et al reported an incidence of $27 \%$ of febrile UTI after endoscopic treatment in their series of 45 patients after a median follow-up of 2.9 years and 2.5 years for the infection-free group and the infection group, respectively. ${ }^{9}$ Traxel et al reported an incidence of febrile UTIs of 3.5\% after a mean follow-up of 2.6 years. ${ }^{5}$ The study performed by Chertin et al reported that the incidence of febrile UTI after a median follow-up of 13 years (range, $1-20$ years) was 2.2\%. ${ }^{4}$ In most of these studies, the follow-up period is short, from 2.6 years to 5 years, except for the study performed by Chertin et al. In our large series of patients, followed for a period of 3.5 to 13.5 years (median, 7.6 years), the incidence of febrile UTIs was $5.7 \%$. In children with post-treatment febrile UTI who underwent a repeat VCUG, the incidence of recurrent VUR is reported to be between $35 \%{ }^{8}$ and $82 \% .^{9}$ Repeat VCUG also showed neocontralateral VUR in as many as $9 \%{ }^{9}$ of patients. In our study, the occurrence of recurrent or neocontralateral VUR was low and noted in $19 \%$ of the children with post-treatment febrile UTI who underwent repeat VCUG.

E coli was the most common causative organism in $90 \%$ of children who had UTI after resolution of VUR in our study. This finding is similar to that of Wadie et al, who found an E coli UTI in $82 \%$ of a post-injection group. ${ }^{15}$ In our study, febrile UTI developed in most children (55\%) in their first year, after resolution of VUR. In their series, Elmore et al have reported that UTI developed within the first year after successful treatment in $83 \%$ of children in the Dx/HA group and $86 \%$ in the open surgery group. ${ }^{6}$

One of the main goals of treating the child with VUR is prevention of recurring febrile UTIs. Several large, prospective, randomized controlled trials have shown little to no benefit of medical therapy for reducing the incidence of febrile UTI or renal scarring. ${ }^{16}$ Surgical resolution of VUR generally reduces the risk of febrile UTIs. Therefore, in the recent updated American Urological Association Guidelines on Management of Primary VUR, surgical intervention for VUR, including both open and endoscopic methods, were included as a management option. ${ }^{16}$

Recently, the Swedish Reflux Trial in Children recruited children between 1 and 2 years old with grade III to IV VUR for a prospective, open, randomized controlled multicenter study. Children were treated in 3 groups, including low-dose antibiotic prophylaxis, endoscopic therapy, and a surveillance group on antibiotics only for febrile UTI. After 2 years, endoscopic treatment results were significantly better than the spontaneous resolution rate or downgrading in the prophylaxis and surveillance groups. ${ }^{17}$ Furthermore, they noted a high rate of recurrent febrile UTI in girls older than 1 year, but not in boys. Although they found that 23\% of the girls in the endoscopic group had postoperative febrile recurrent UTI, recurrent postoperative UTIs were significantly decreased compared with those in control subjects in the surveillance group. ${ }^{18}$ 
Table IV. Incidence of febrile UTIs, follow-up, and injectables in other series

\begin{tabular}{|c|c|c|c|c|}
\hline References & Patients, $n$ & Injectables & Mean/median follow-up, years (range) & Febrile UTI \% \\
\hline Elder et $\mathrm{al}^{14}$ & 5527 & $\begin{array}{l}51 \% \text { polytetrafluoroethylene } \\
21 \% \text { collagen } \\
10 \% \text { Dx/HA } \\
8 \% \text { polydimethylsiloxane } \\
2 \% \text { chondrocytes } \\
2 \% \text { blood } \\
8 \% 2 \text { or more injectables }\end{array}$ & Not mentioned & $0.75 \%$ \\
\hline 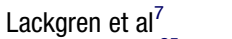 & 228 & $\mathrm{DX} / \mathrm{HA}$ & Mean, 5 (2-7.5) & $3.5 \%$ \\
\hline Sternberg et $\mathrm{al}^{25}$ & 179 & $\mathrm{Dx} / \mathrm{HA}$ & $(6-11)$ & $3.4 \%$ \\
\hline Chi et $\mathrm{al}^{8}$ & 167 & $\mathrm{Dx} / \mathrm{HA}$ & Median, $2.6(0.6-4.4)$ & $12 \%$ \\
\hline Elmore et $\mathrm{al}^{6}$ & 40 & $\mathrm{Dx} / \mathrm{HA}$ & Mean, $3.6(3.2-3.9)$ & $5 \%$ \\
\hline Sedberry-Ross et al ${ }^{9}$ & 45 & $\mathrm{Dx} / \mathrm{HA}$ & Median, 2.5 & $27 \%$ \\
\hline Chertin et $\mathrm{al}^{4}$ & 507 & $\begin{array}{l}\text { Polytetrafluoroethylene: } 369 \text { pts } \\
\text { Dx/HA: } 138 \text { pts }\end{array}$ & Median, $13(1-20)$ & $2.2 \%$ \\
\hline Traxel et al ${ }^{5}$ & 311 & $\mathrm{Dx} / \mathrm{HA}$ & Mean, 2.6 (0.3-5.4) & $3.5 \%$ \\
\hline Brandstrom et al ${ }^{18 *}$ & 66 & $\mathrm{Dx} / \mathrm{HA}$ & Median, 2.05 & $21 \%$ \\
\hline Current series & 1271 & $\begin{array}{l}\text { Polytetrafluoroethylene: } 253 \text { pts } \\
\text { Dx/HA: } 1018 \text { pts }\end{array}$ & Median, 7.6 (3.5-13.5) & $5.7 \%$ \\
\hline
\end{tabular}

*Prospective, randomized controlled study.

Dysfunctional voiding syndrome and BBD refer to abnormalities of storage and emptying, often including constipation. ${ }^{16}$ The bladder part of this syndrome can be recognized as dysfunctional voiding. ${ }^{19}$ Several studies have shown risk factors for UTI after correction of VUR. It has been reported that female sex and bilateral VUR are risk factors for post-treatment UTI. ${ }^{15}$ Sedberry-Ross et al stated that 9 of 12 children (75\%) in the infection group had a history of dysfunctional elimination, and 9 of 12 children (75\%) had multiple preoperative febrile UTIs. ${ }^{9}$ The incidence of renal scarring was not statistically significant between the UTI and the no UTI group. However, they stated that there was a high number of renal scars in the entire cohort group. Lackgren et al reported that $50 \%$ of children with postoperative UTI had dysfunctional voiding. ${ }^{7}$ Chi et al showed that girls, children with recurrent preoperative UTIs, older children, and children with voiding dysfunction were more likely to have a UTI after endoscopic treatment. ${ }^{8}$ They also performed univariate analysis and found that the number of preoperative UTIs and dysfunctional voiding were significant predictors of post-injection UTI. With their multivariate analysis, however, only recurrent preoperative UTI was found to be an independent risk factor. Traxel et al found with multivariate analysis that recurrent UTI and bladder dysfunction were independent predictors for postoperative UTI. ${ }^{5}$ Female sex and preoperative renal scarring were not significant. In the recently updated American Urological Association guidelines, the rate of UTI after open or endoscopic surgery was greater in children with BBD (22\%) than children without BBD $(5 \%){ }^{16}$

It is believed that endoscopic treatment of VUR in children with dysfunctional voiding has an unfavourable outcome. ${ }^{20}$ This has been attributed to the displacement of the Dx/HA implant in children with voiding dysfunction because high intravesical pressure caused by uninhibited detrusor contractions may cause displacement of the Dx/HA implant. Cappozza et al found a displaced implant in 27 children at re-treatment after initial treatment failure, and of these 27 children, 25 had dysfunctional voiding. ${ }^{20}$ Since we started treating VUR endoscopically, we have not considered BBD as a contraindication to endoscopic treatment. We only treat dysfunctional voiding when it persists after successful correction of VUR. In our series, 23 of the 73 children (31.5\%), predominantly girls with febrile UTIs, had a positive history of BBD after correction of VUR, whereas only 92 of the 1198 children $(7.6 \%)$ who had no UTIs after endoscopic correction of VUR had history of BBD. In a study of 107 girls with reflux, it was revealed that approximately $50 \%$ had voiding dysfunction, and they were 4 times more likely to experience breakthrough UTIs. ${ }^{21}$ The low incidence of BBD in our patients after successful correction of VUR with endoscopic treatment suggests that VUR may be contributory to dysfunctional voiding and resolution of VUR may improve dysfunctional voiding. Correction of VUR in our series cured dysfunctional voiding in $74 \%$ of children. Similar, Lackgren et al reported that injection of Deflux cured VUR in 45 patients $(83 \%) .{ }^{22}$ Residual urine and incomplete bladder emptying play an important role in the origin of infections. It has been reported that voiding dysfunction is common in girls with infections. As many as $66 \%$ of girls with voiding dysfunction have UTIs. ${ }^{23}$ In a retrospective study of medically treated children with vesicouerteral reflux, the incidence of breakthrough infection was increased in children with urgency and incontinence. ${ }^{24}$ It is believed that VUR correction decreases the risk of febrile UTI and thus prevents renal parenchymal damage. Risk factors that may predict febrile UTIs after correction of VUR need to be addressed. Patients, especially girls, and children with BBD before and after correction of VUR require special attention.

An important limitation of this study is that we did not perform VCUG in all children with febrile UTI after resolution of VUR. Children who had two or more febrile UTIs and children who showed prominence of renal collecting system on ultrasound scanning after the first febrile UTI underwent VCUG. It therefore is possible that we may have missed lowgrade VUR in some patients. It is a retrospective study, and it 
is likely that a few patients may not have reported the occurrence of febrile UTI after resolution of VUR or minor BBD. Furthermore, the DMSA scan was performed in 1130 of 1271 patients (89\%) and may have missed mild renal scarring in some patients.

Although one could argue that children with BBD could have been biased by their young age, children with BBD in our study were 3.0 to 12.1 years (median, 10.2 years) at the time of injections. Furthermore, children who have BBD after endoscopic injection received a diagnosis at a median age of 6.5 years.

Submitted for publication Aug 2, 2011; last revision received Dec 2, 2011; accepted Dec 16, 2011.

Reprint requests: Professor Prem Puri, MS, FRCS, FRCS (Ed), FACS, FAAP (Hon), President, National Children's Research Centre, Our Lady's Children's Hospital, Dublin-12, Ireland. E-mail: prem.puri@ucd.ie

\section{References}

1. Smellie JM, Barratt TM, Chantler C, Gordon I, Prescod NP, Ransley PG, et al. Medical versus surgical treatment in children with severe bilateral vesicoureteric reflux and bilateral nephropathy: a randomised trial. Lancet 2001;357:1329-33.

2. Hoberman A, Charron M, Hickey RW, Baskin M, Kearney DH, Wald ER. Imaging studies after a first febrile urinary tract infection in young children. N Engl J Med 2003;348:195-202.

3. Marra G, Oppezzo C, Ardissino G, Dacco V, Testa S, Avolio L, et al. Severe vesicoureteral reflux and chronic renal failure: a condition peculiar to male gender? Data from the ItalKid Project. J Pediatr 2004;144:677-81.

4. Chertin B, Natsheh A, Fridmans A, Shenfeld OZ, Farkas A. Renal scarring and urinary tract infection after successful endoscopic correction of vesicoureteral reflux. J Urol 2009;182:1703-6.

5. Traxel E, DeFoor W, Reddy P, Sheldon C, Minevich E. Risk factors for urinary tract infection after dextranomer/hyaluronic acid endoscopic injection. J Urol 2009;182:1708-12.

6. Elmore JM, Kirsch AJ, Heiss EA, Gilchrist A, Scherz HC. Incidence of urinary tract infections in children after successful ureteral reimplantation versus endoscopic dextranomer/hyaluronic acid implantation. J Urol 2008;179:2364-7. discussion 7-8.

7. Lackgren G, Wahlin N, Skoldenberg E, Stenberg A. Long-term followup of children treated with dextranomer/hyaluronic acid copolymer for vesicoureteral reflux. J Urol 2001;166:1887-92.

8. Chi A, Gupta A, Snodgrass W. Urinary tract infection following successful dextranomer/hyaluronic acid injection for vesicoureteral reflux. J Urol 2008;179:1966-9.

9. Sedberry-Ross S, Rice DC, Pohl HG, Belman AB, Majd M, Rushton HG. Febrile urinary tract infections in children with an early negative voiding cystourethrogram after treatment of vesicoureteral reflux with dextranomer/hyaluronic acid. J Urol 2008;180:1605-9. discussion 10.

10. Menezes MN, Puri P. The role of endoscopic treatment in the management of grade v primary vesicoureteral reflux. Eur Urol 2007;52: 1505-9.

11. Puri P, Mohanan N, Menezes M, Colhoun E. Endoscopic treatment of moderate and high grade vesicoureteral reflux in infants using dextranomer/hyaluronic acid. J Urol 2007;178:1714-6. discussion 7.

12. Puri P, Pirker M, Mohanan N, Dawrant M, Dass L, Colhoun E. Subureteral dextranomer/hyaluronic acid injection as first line treatment in the management of high grade vesicoureteral reflux. J Urol 2006;176:1856-9. discussion 9-60.

13. Jodal U, Smellie JM, Lax H, Hoyer PF. Ten-year results of randomized treatment of children with severe vesicoureteral reflux. Final report of the International Reflux Study in Children. Pediatr Nephrol 2006;21: 785-92.

14. Elder JS, Diaz M, Caldamone AA, Cendron M, Greenfield S, Hurwitz R, et al. Endoscopic therapy for vesicoureteral reflux: a meta-analysis. I. Reflux resolution and urinary tract infection. J Urol 2006;175:716-22.

15. Wadie GM, Tirabassi MV, Courtney RA, Moriarty KP. The deflux procedure reduces the incidence of urinary tract infections in patients with vesicoureteral reflux. J Laparoendosc Adv Surg Tech A 2007;17:353-9.

16. Peters CA, Skoog SJ, Arant BS Jr, Copp HL, Elder JS, Hudson RG, et al. Summary of the AUA Guideline on Management of Primary Vesicoureteral Reflux in Children. J Urol 2010;184:1134-44.

17. Holmdahl G, Brandstrom P, Lackgren G, Sillen U, Stokland E, Jodal U, et al. The Swedish reflux trial in children: II. Vesicoureteral reflux outcome. J Urol 2010;184:280-5.

18. Brandstrom P, Esbjorner E, Herthelius M, Swerkersson S, Jodal U, Hansson S. The Swedish reflux trial in children: III. Urinary tract infection pattern. J Urol 2010;184:286-91.

19. Sillen U. Bladder dysfunction and vesicoureteral reflux. Adv Urol 2008;815472. Epub 2008 Nov 4.

20. Capozza N, Lais A, Matarazzo E, Nappo S, Patricolo M, Caione P. Influence of voiding dysfunction on the outcome of endoscopic treatment for vesicoureteral reflux. J Urol 2002;168:1695-8.

21. Snodgrass W. The impact of treated dysfunctional voiding on the nonsurgical management of vesicoureteral reflux. J Urol 1998;160:1823-5.

22. Lackgren G, Skoldenberg E, Stenberg A. Endoscopic treatment with stabilized nonanimal hyaluronic acid/dextranomer gel is effective in vesicoureteral reflux associated with bladder dysfunction. J Urol 2007;177: 1124-8. discussion 8-9.

23. Snodgrass W. Relationship of voiding dysfunction to urinary tract infection and vesicoureteral reflux in children. Urology 1991;38:341-4.

24. van Gool JD, Hjalmas K, Tamminen-Mobius T, Olbing H. Historical clues to the complex of dysfunctional voiding, urinary tract infection and vesicoureteral reflux. The International Reflux Study in Children. J Urol 1992;148:1699-702.

25. Stenberg A, Lackgren G. Treatment of vesicoureteral reflux in children using stabilized non-animal hyaluronic acid/dextranomer gel (NASHA/DX): a long-term observational study. J Pediatr Urol 2007;3:80-5. 